\title{
Reform and Exploration of Computer Science and Technology Major in Applied Undergraduate Colleges Based on CDIO
}

\author{
Lin Chen ${ }^{1,}$, Linxiang Shi ${ }^{1, b}$ \\ ${ }^{1}$ College of Engineering, Shanghai Polytechnic University, Shanghai 201209, China \\ achenl@sspu.edu.cn, ${ }^{b}$ lxShi@sspu.edu.cn
}

Keywords: CDIO; applied undergraduate college; computer; reform and exploration

\begin{abstract}
With the computer education development, the graduates of computer education have increased significantly in recent years. However, the quality is not satisfactory. So colleges and universities, especial local colleges and universities should carry out the education reform. CDIO includes conceive, design, implement and operate stages which represents a successful international education mode. The corresponding CDIO reform and exploration of computer science and technology major of applied undergraduate colleges is presented in the paper, also including the reform of course architecture, teaching mode and test methods.
\end{abstract}

\section{Introduction}

The teaching model based on the concept of CDIO represents the latest achievement of the international engineering education reform in recent years. CDIO includes four stages of Conceive, Design, Implement and Operate [1]. It applies the full life cycle idea of product development to the teaching process, and it is a complete set of engineering education concept and implementation system [2]. Moreover, CDIO allows students to learn the engineering theory knowledge, accumulate engineering experience and improve the comprehensive application of professional knowledge in a practical way. Furthermore, the ability not only includes the subject knowledge, but also includes students' lifelong learning ability, communication skills, engineering design and development ability under the real enterprise and social environment [3].

With the development of the economy and society, the number of students and majors of computer science and technology have increased rapidly. It is reported that the number of majors of computer science and technology is the top one [4]. However, because of the influences of many factors such as faculty, student quality, experimental sites and educational mechanism, the graduate quality of CS in local universities is not satisfactory, and it is difficult to meet the requirements of new era of engineering education. Thus, there is an urgent need for engineering education reform. CDIO is an excellent education mode, and suitable to major reform of local universities [5]. 


\section{Major Status}

Shanghai Polytechnic University is a local university of Shanghai. As one of the key majors, the major of Computer Science and Technology began to recruit undergraduate students since 2004. It joined the "Excellent Engineering Plan" of the Ministry of Education, and is now one of the pilot specialty of applied undergraduate of Shanghai. The computer science and technology specialty of our university focuses on the training of applied advanced engineering talents, and its direction of specialty is embedded system. After years of reform, some achievements have been made, but there are still some problems:

- The current arrangement of practical training and theory teaching is out of line. A large portion of classes are arranged in practice teaching, the CDIO engineering education method though is not carried out. Furthermore, the idea of "learn by doing" is not fully embodied. The students have not mastered the theory thoroughly, and their practice ability are not strong as well.

- The current education plays emphasis on the cultivation of professional knowledge, and does not take the influence of lifelong learning ability, team cooperation, society and environment into consideration. So the training of students is not comprehensive.

- The current form of teaching and assessment is relatively simple. Most courses are taught by traditional ways with blackboard and chocks. The offline and online combined methods are not adopted by most teachers to improve the studying quality. Moreover, the paper test is used in most courses. The test mode is simple and single. Worse, the teaching and study process are not evaluated, and the study quality during class is not graded.

The computer science and technology major of our university follows the CDIO based engineering talent training mode, reconstruct the curriculum system according to "Excellent Engineering Plan". Especially, we have constructed a multi-dimensional and multi-level training system for professional innovation practice ability.

\section{Idea of Reform}

\subsection{Reconstruct curriculum system}

Establish mutually supportive course group. Our training goal is the whole design and development ability of embedded system. Then, according to the goal, we decompose the first level project, second level project and third level project. The second level projects are related to the knowledge of course groups, and the third level projects mainly focus on one special course.

\subsection{Comprehensive ability training}

Except for the professional knowledge, group cooperation, system integration and other ability are all integrated into the cultivation plan. For example, in the project course, we also develop students how to cooperate with each other to complete successfully an practical engineering project.

\subsection{Reform teaching and test methods}

Except for the offline teaching, online teaching methods are also integrated into the study activities. Moreover, they should take much more time on project beyond class. On the other hand, except for the final paper test, we should play more importance on the study process, and test it, evaluated it, which amount to most of the final scores of students. 


\section{Course Architecture Building}

The course architecture built according to CDIO is shown in Fig.1

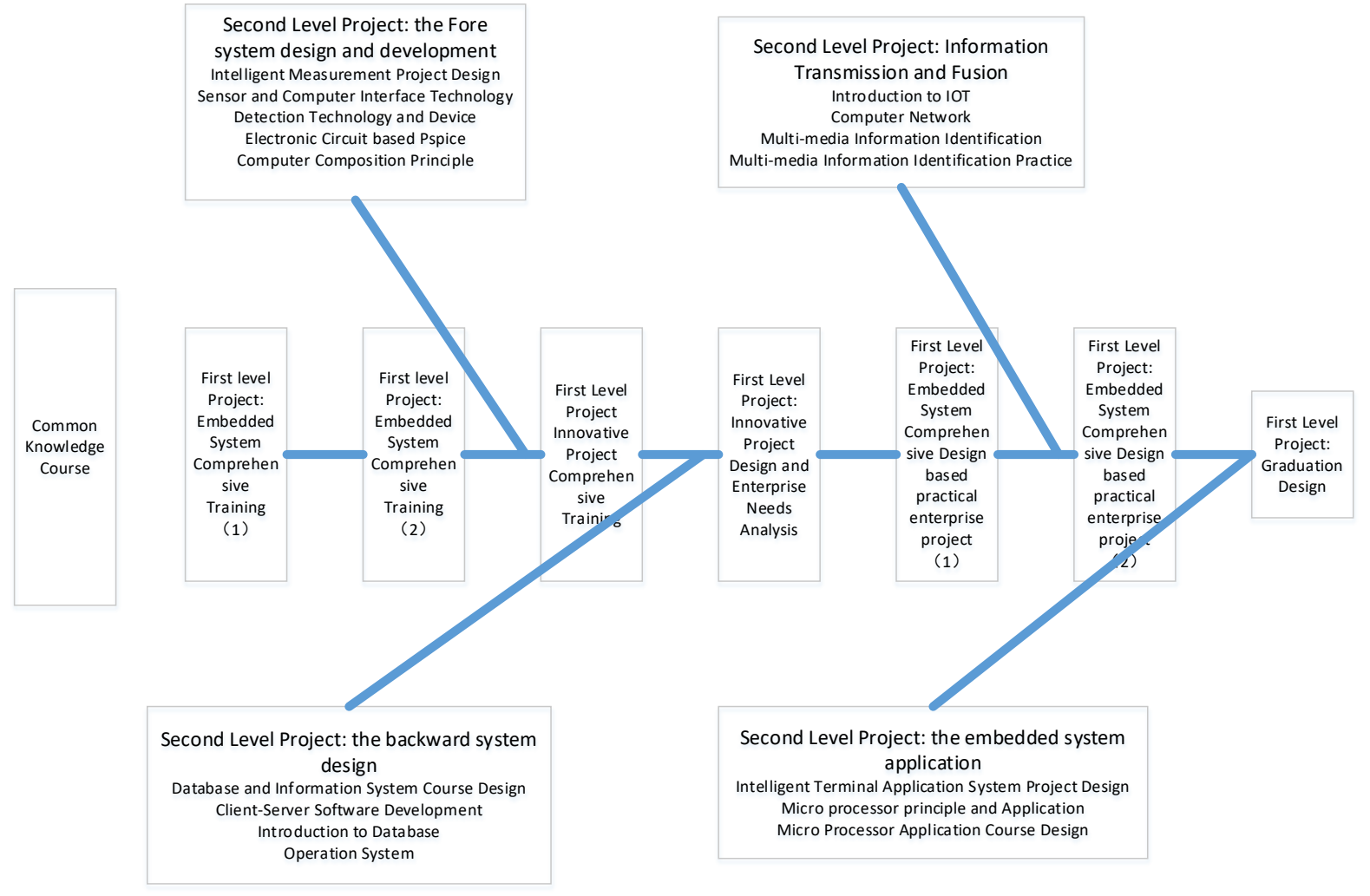

Fig. 1 Course Architecture

The first level projects are arranged from the autumn semester of second year. Each semester, one by one, progressively, spiral trains students' engineering design and development ability. They include: embedded system design comprehensive training (1) and (2), innovative project design comprehensive training, innovative project design and enterprise demand analysis, embedded system integrated design based on enterprise project (1) and (2), and finally the graduation design.

The second level projects are based on the design and development requirements of the embedded system, which are rely on the course groups, and include:

The design and development of the fore computer course group: intelligent detection project design, sensor and computer interface technology, measurement technology and device, introduction to electronic circuit based Pspice, computer composition principle.

The design and development of the backward computer course group: database and information system course design, client-server software development, introduction to database and operation system.

The information transmission and fusion course group: computer network, introduction to IOT, multi-media information identification, and multi-media information identification practice.

The embedded system application course group: intelligent terminal application system project design, micro-processor principle and application, micro-processor application course design.

\section{Reform of Teaching and Test Methods}

The teaching method uses the "Internet+ Education", by combining online and offline teaching mode, the MOOC, Micro Class, Flipped Class and other teaching methods. Before class, the preview 
and autonomous cooperative learning based tasks list; in class, interactive learning between teachers and students; after class, review of knowledge based review task list. The whole teaching process is organically integrated online and offline ways to meet the individual needs of every student and enable students to acquire better learning experience and ability.

Diversified test and assessment methods are also adopted. The single paper test mode is changed, and classroom tests, extracurricular projects, practice, test, examination and other ways are all adopted to evaluate and assess the learning process and improve the teaching in time. The score methods include: small paper/reviews, student lectures, group cooperation, scoring with each other, project defense, and competition. We should strengthen process assessment and record, and improve the proportion of process assessment to final achievement.

\section{Conclusion}

As one of the mainstream model of engineering education, CDIO has received more and more attention from universities. As one local applied undergraduate university, SSPU has recently carried out the CDIO education reform, and the major of computer science and technology is the first batch of CDIO reform pilot major. We reconstruct the course architecture, change the teaching method, improve the test and assessment system. Finally, the education quality has greatly increased.

\section{References}

[1] P.H. Gu, M. F. Shen, X. H. Lu, Rethinking Engineering Education: The CDIO Approach, Higher Education Press, Bei Jing, 2012.

[2] W. Song, Research on the Reform of University Computer Teaching Based on CDIO, Education Teaching Forum, 2017, No.29: 119-120.

[3] X. L. Liao, X. H. Yu, S. J. Zhang et al, Experimental Teaching Reform of Computer specialty based CDIO Idea, Computer Education, 2018, No.2: 47-50.

[4] H. Zhang, X. B. Wen, J. S. Wang, Reaching Reform of Computer Specialty based CDIO mode, Computer Education, 2010, No.11: 71-73.

[5] A. J. Xie, Y. W. Tao, S. P. Luo, et al, Practice Teaching System Construction of Universities based CDIO Idea, Journal of Changzhou University (Social Science Edition), 2015, No. 3: 118-121. 